\title{
Synthesis and Expansion of Bicyclic Enol Ether: A Probable Precursor for the Synthesis of Macrolide ( \pm )-Pyrenophorin
}

\author{
Maísa B. Costa, ${ }^{*, a, \# ~ M a r c o s ~ P . ~ M a r t i n s, ~}{ }^{a}$ Hugo C. de Araújo ${ }^{b}$ and Inês S. Resck ${ }^{b}$ \\ ${ }^{a}$ Laboratório de Síntese, Isolamento e Modificações de Compostos Orgânicos, \\ Universidade Estadual de Goiás, Campus Henrique Santillo, BR 153, No. 3105, \\ Fazenda Barreiro do Meio, Setor Arco Verde, CP 459, 75132-400 Anápolis-GO, Brazil \\ ${ }^{b}$ Instituto de Química, Universidade de Brasília, Campus Darcy Ribeiro, \\ CP 4478, 70910-970 Brasília-DF, Brazil
}

\begin{abstract}
A convenient procedure for the synthesis and expansion of bicyclic rings has been developed for the production of probable precursors of non-racemic pyrenophorin, an antibiotic dilactone. The major highlight for this new synthetic methodology came from the use of a readily available reagent of easy manipulation, 9-oxabicyclo[3.3.1]nonane-2,6-diol, for the preparation of the bicyclic intermediate, which sequentially was subjected to oxidative cleavage with butyl nitrite resulted in an isomeric mixture, a dioximedilactone and diisoxazoledilactone.
\end{abstract}

Keywords: enol ether, ring expansion, macrolides, pyrenophorin

\section{Introduction}

The structural diversity of the macrolides represents an interesting synthetic challenge for the obtainment of molecules with medium or macrocyclic sizes. Following the research conducted in our laboratory to obtain macrocyclic lactones, it was developed the synthesis of a precursor that will be later applied to the racemic synthesis of the natural 16-membered macrolide pyrenephorin ${ }^{1}(\mathbf{1})$, a macrolactone dimer with high biological potential (Figure 1).

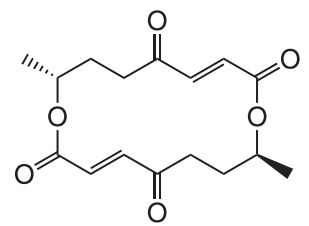

$(R, S)-( \pm)$-pyrenophorin (1)

Figure 1. Natural macrolide 1.

The bioactive metabolite $\mathbf{1}$, pyrephorin, was isolated from the pathogenic fungi Pyrenophora avenae and Stemphylium radicinum, ${ }^{1}$ and the cultures of Drechslera avenae acting as a phytotoxin on leaves segments of Avena sterilis. ${ }^{2}$

*e-mail: maisabc@gmail.com, maisa.costa@ueg.br

${ }^{\#}$ Synthetic part of this research was initially developed at the Instituto de Química, Universidade de Brasília, and is related to the doctoral thesis.
In as much of the wide spectrum of biological activities, mainly as antibiotics, several synthetic methodologies for the synthesis of this 16-member macrolide, racemic or chiral, have been reported in the literature. Many are based on the lactonization and the dimeric cyclization of seco- $\omega$-hydroxy-acid derivatives and $\gamma$-oxo- $\alpha, \beta$-unsaturated derivatives, as well as the formation of intramolecular $\mathrm{C}-\mathrm{C}$ bonds, in addition to cyclodimerization under Mitsunobu conditions. $^{3-7}$

Therefore, in this article, a new procedure is demonstrated to obtain potential synthetic precursors that may lead to the synthesis of ( \pm )-pyrenophorin (1) through the use of oxidative ring expansion methodology. ${ }^{8}$

\section{Experimental}

\section{General methods}

All reagents used were of analytical grade. The products of all reactions were monitored by capillary gas chromatography on VARIAN STAR 3400 CX equipment using DB-5 and DB-1 capillary columns of length equal to $30 \mathrm{~m} \times 25 \mathrm{~mm}$, with a temperature range of $120-190{ }^{\circ} \mathrm{C}$, injector temperature of $250^{\circ} \mathrm{C}$ and the detector of $300^{\circ} \mathrm{C}$. The DEX-CB capillary chiral column with a length equal to $25 \mathrm{~m} \times 25 \mathrm{~mm}$, with a temperature range of $160-200^{\circ} \mathrm{C}$, injector temperature of $250^{\circ} \mathrm{C}$ and detector of $300{ }^{\circ} \mathrm{C}$, was 
used in specific cases. The products were purified on flash chromatographic column using silica gel (230-400 mesh). The melting points were determined in the Köfler block and were recorded without correction. The ${ }^{1} \mathrm{H}$ and ${ }^{13} \mathrm{C}$ (single and two-dimensional) nuclear magnetic resonance (NMR) spectra were obtained on the spectrometer. The probes used were ATB and $\mathrm{SW}$, with $5 \mathrm{~mm}$ internal diameter, at room temperature with $45^{\circ}$ pulse for hydrogen and carbon. Chemical displacements $(\delta)$ in ${ }^{1} \mathrm{H}$ NMR, with deuterated solvents $\mathrm{CDCl}_{3}$ and DMSO- $d_{6}$, were referenced with TMS and the DMSO residue ( $\delta 2.49)$, respectively. In ${ }^{13} \mathrm{C}$ NMR, they were referenced with $\delta 77.0\left(\mathrm{CDCl}_{3}\right)$ and $\delta 39.7$ (DMSO- $d_{6}$ ). The multiplicities were defined in the usual way: s (singlet), d (doublet), dd (double doublet), $\mathrm{t}$ (triplet), q (quartet), m (multiplet). Low resolution mass spectra were obtained from the Shimadzu GC-17A (Civil Police, Distrito Federal) equipment. High resolution mass spectra were obtained from VG-auto SPEC (IQ, Unicamp) equipment. Elemental analyzes were obtained from the Analytische Laboratorien Prof. Dr. H. Malissa und G. Reuter GmbH.

\section{Synthesis of 9-oxabicyclo[3.3.1]nonane-2,6-diol (3)}

The isomeric mixture of 9-oxabicyclo[3.3.1]nonane2,6-diol (3) and 9-oxabicyclo[4.2.1]nonane-2,5-diol (3a) was prepared by the oxidation of cycloocta-5-diene (2) $(1.18 \mathrm{~mol})$ under treatment with formic acid ${ }^{9-11}(1.06 \mathrm{~mol})$ and under vigorous magnetic stirring and, in an ice bath, $30 \% \mathrm{H}_{2} \mathrm{O}_{2}(300 \mathrm{~mL}, 9.20 \mathrm{~mol})$ was added dropwise. After the addition, the formation of a biphasic mixture was observed, which was maintained at $50{ }^{\circ} \mathrm{C}$ (internal temperature). The mixture became homogeneous after two days under magnetic stirring at $50{ }^{\circ} \mathrm{C}$. Subsequently, $10 \% \mathrm{Pd} / \mathrm{C}(0.10 \mathrm{~g})$ was added to decompose the excess of $\mathrm{H}_{2} \mathrm{O}_{2}$. This step was monitored with $\mathrm{KI} / \mathrm{starch}$ indicator paper. The solution was filtered under celite and subjected to liquid-liquid extraction with ethyl acetate for $72 \mathrm{~h}$. The organic phase was concentrated on a rotary evaporator in which provided a yellow solid of melting point equal to $55-58{ }^{\circ} \mathrm{C}$ in $85 \%$ yield $(1.50 \mathrm{~mol})$. The diol 3 was isolated from the isomeric mixture, $\mathbf{3}$ and $\mathbf{3 a}$, by successive recrystallizations from ethyl acetate. Chromatographic analysis and NMR confirmed the structure and purity of compound $\mathbf{3}$ (Scheme 1).

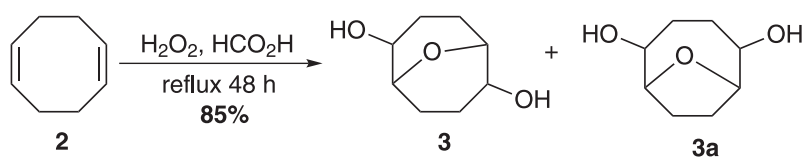

Scheme 1. Reaction conditions for synthesis of diol 3.
9-Oxabicyclo[3.3.1]nonane-2,6-diol (3)

White solid, m.p. $124-125{ }^{\circ} \mathrm{C}$; IR $(\mathrm{KBr}) \mathrm{v} / \mathrm{cm}^{-1}$ 3422, 3282, 2949, 2909, 1483, 1079, 1062, 974; ${ }^{1} \mathrm{H}$ NMR (300 MHz, DMSO- $\left.d_{6}\right) \delta 4.78(\mathrm{~d}, J 6 \mathrm{~Hz}, \mathrm{OH}), 3.68(2 \mathrm{H})$, $3.51(\mathrm{dd}, J 5.0,5.0 \mathrm{~Hz}, 2 \mathrm{H}), 2.01-1.88(\mathrm{~m}, 2 \mathrm{H}), 1.74-1.53$ $(\mathrm{m}, 6 \mathrm{H}) ;{ }^{13} \mathrm{C}$ NMR $\left(75 \mathrm{MHz}\right.$, DMSO- $\left.d_{6}\right) \delta 69.4,67.5,28.8$, 22.0; anal. calcd. for $\mathrm{C}_{8} \mathrm{H}_{14} \mathrm{O}_{3}\left(158.0946 \mathrm{~g} \mathrm{~mol}^{-1}\right)$ : C, 54.53; H, 9.15\%. Found: C, 54.52; H, 9.11\%.

\section{Synthesis of 2,6-dioxo-9-oxabicyclo[3.3.1]nonane (4)}

The 2-iodoxybenzoic acid ${ }^{12}(8.40 \mathrm{~g} ; 30.0 \mathrm{mmol})$ was added to the solution of diol $3(1.58 \mathrm{~g}, 10.0 \mathrm{mmol})$ in ethyl acetate $(60 \mathrm{~mL})$ and stirred magnetically at $80^{\circ} \mathrm{C}$. After $6 \mathrm{~h}$ of reaction, the suspension was filtered through a column of florisil (60-100 mesh) washed with ethyl acetate $(2 \times 30 \mathrm{~mL})$ and evaporated. The product obtained, recrystallized from isopropanol, with degree of high purity demonstrated by gas chromatographic was characterized as a white solid $\left(9.80 \mathrm{mmol} ; 99 \%\right.$ m.p. $\left.49-51{ }^{\circ} \mathrm{C}\right)$ (Scheme 2).

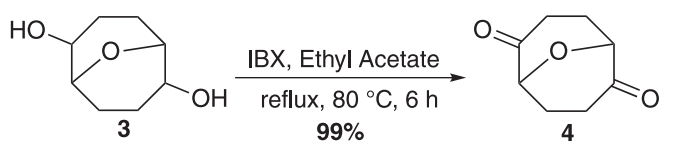

Scheme 2. Reaction conditions for synthesis of diketone 4.

\section{2,6-Dioxo-9-oxabicyclo[3.3.1]nonane (4)}

White solid, m.p. $49-51^{\circ} \mathrm{C}$; IR (KBr) v / $\mathrm{cm}^{-1} 3409$, 2950, 2927, 1715, 1455, 1299, 1242, 1189, 1127; ${ }^{1} \mathrm{H}$ NMR $\left(300 \mathrm{MHz}, \mathrm{CDCl}_{3}\right) \delta 4.38(\mathrm{~m}, 2 \mathrm{H}), 2.80-2.69(\mathrm{~m}, 2 \mathrm{H})$, 2.57-2.38 (m, 4H), 2.17-2.04 (m, 2H); ${ }^{13} \mathrm{C} \mathrm{NMR}(75 \mathrm{MHz}$, $\left.\mathrm{CDCl}_{3}\right) \delta$ 209.6, 75.7, 33.5, 25.0; anal. calcd. for $\mathrm{C}_{8} \mathrm{H}_{10} \mathrm{O}_{3}$ (154.0629 $\mathrm{g} \mathrm{mol}^{-1}$ ): C, 62.33; H, 6.54\%. Found: C, 62.20; $\mathrm{H}, 6.51 \%$.

Synthesis of 2,8-dimethyl-3,4,6,8,9,10,11,12-octahydro$2 H, 5 H$-pyrano[2',3',5,6]cycloocta[1,2-b]pyran-6,12-diol (7)

Diketone 4 (1.54 g, $10.0 \mathrm{mmol}$ ), anhydrous cyclohexane $(50 \mathrm{~mL})$, morpholine $(4.40 \mathrm{~mL}, 30.0 \mathrm{mmol})$ and nafion $417^{\circledR}$ $(2.00 \mathrm{~mm})$ were refluxed under stirring on a Dean- Stark for $48 \mathrm{~h}$ to convert 4 into enamine 5 . The solvent (cyclohexane) and the residual reactant (morpholine) were removed under reduced pressure (1.00 torr) resulting in a yellowish solid ( $2.67 \mathrm{~g} ; 9.10 \mathrm{mmol} ; 90 \%)$ which was used in the next step without prior purification.

The solid crude enamine 5 ( $9.10 \mathrm{mmol})$ was subjected to alkylation (Michael addition) in anhydrous dioxane $(50 \mathrm{~mL})$ and methyl vinyl ketone $(2.50 \mathrm{~mL}, 30.0 \mathrm{mmol})$ was dripped, under controlled conditions $\left(\mathrm{N}_{2}\right.$ atmosphere 
and $\mathrm{CaCl}_{2}$ tube). After $24 \mathrm{~h}$ reflux, the residual solvents and reagents were removed under reduced pressure to provide a viscous yellowish liquid. $\mathrm{NaBH}_{4}(0.76 \mathrm{~g}, 20.0 \mathrm{mmol})$ was added to the solution of the alkylated enamine $\mathbf{6}$ in ethanol $(25 \mathrm{~mL})$, cooled in an ice bath. The reagent suspension was stirred for $0.5 \mathrm{~h}$ at that temperature, then for $2 \mathrm{~h}$ at room temperature.

After this, the residual $\mathrm{NaBH}_{4}$ was decomposed with $20 \%$ aqueous $\mathrm{HCl}$ solution (ca. $15 \mathrm{~mL}$ ). Then a further $30 \mathrm{~mL}$ of $20 \%$ aqueous $\mathrm{HCl}$ solution and fourteen hour reflux was added to occur the hydrolysis and cyclization of the reduced product 7 (Scheme 3). The reaction was cooled and then the aqueous phase was extracted with chloroform $(3 \times 30 \mathrm{~mL})$, and the combined organic phases were washed with saturated $\mathrm{NaHCO}_{3}$ solution $(3 \times 30 \mathrm{~mL})$ and brine $(3 \times 20 \mathrm{~mL})$. After manipulation, a yellowish viscous liquid (1.72 g, $6.10 \mathrm{mmol}, 81 \%)$ was obtained. Purification by dry flash chromatography column $(10 \%$ hexane/ethyl acetate) yielded yellowish crystals (1.42 g, $5.00 \mathrm{mmol}, 50 \%$ ) which recrystallized from ethyl acetate or dichloromethane provided white crystals (m.p. $102-103{ }^{\circ} \mathrm{C}$; $41 \%$ ) with $\mathrm{R}_{\mathrm{t}}$ (retention time) $14.18 \mathrm{~min}(50.95 \%)$ and $14.38 \min (49.04 \%)$.

\section{2,8-Dimethyl-3,4,6,8,9,10,11,12-octahydro- $2 \mathrm{H}, 5 \mathrm{H}$ -} pyrano[2',3',5,6]cycloocta[1,2-b]pyran-6,12-diol (7)

White solid, m.p. $102-103{ }^{\circ} \mathrm{C}$; IR $(\mathrm{KBr}) \mathrm{v} / \mathrm{cm}^{-1}$ 3393, 2973, 2928, 2875, 1705, 1449, 1365, 1322, 1219, 1186, 1089, 890, 801, 765; ${ }^{1} \mathrm{H}$ NMR (300 MHz, $\mathrm{CDCl}_{3}$ ) $\delta$ 4.15-4.05 (m, 3H), 3.97-3.89 (m, 3H), 3.82-3.75 (m, 1H), 2.42-1.54 (m, 22H), 1.27 (d, J6.2 Hz, 3H), 1.22 (d, J $6.3 \mathrm{~Hz}$, $3 \mathrm{H}) ;{ }^{13} \mathrm{C} \mathrm{NMR}\left(75 \mathrm{MHz}, \mathrm{CDCl}_{3}\right) \delta 145.5,102.5,102.0$, 72.0, 71.2, 70.8, 68.9, 67.0, 66.8, 30.0, 28.9, 27.9, 25.5, 22.2, 21.2, 19.7; anal. calcd. for $\mathrm{C}_{16} \mathrm{H}_{24} \mathrm{O}_{4}\left(281 \mathrm{~g} \mathrm{~mol}^{-1}\right)$ : C, 68.54; H, 8.63\%. Found: C, 68.42; H, 8.88\%.
Synthesis for the expansion of 2,8-dimethyl3,4,6,8,9,10,11,12-octahydro-2H,5H-pyrano[2', 3', 5,6] cycloocta[1,2-b]pyran-6,12-diol (7)

Butyl nitrite $(0.60 \mathrm{~mL}, 5.00 \mathrm{mmol})$ was added to a solution of enol ether $7(0.28 \mathrm{~g}, 1.00 \mathrm{mmol})$ solubilized in ethanol, kept under ice-bath. The reaction flask was carefully sealed with a rubber septum to prevent the loss of nitrous acid formed with the addition of $10 \% \mathrm{HCl}(5 \mathrm{~mL})$. After $1 \mathrm{~h}$ of stirring at $0{ }^{\circ} \mathrm{C}$, the reaction was allowed to stand at $-18{ }^{\circ} \mathrm{C}$ for 24 hours. The aqueous phase was extracted with dichloromethane $(5 \times 20 \mathrm{~mL})$, and the organic extract was washed with brine $(1 \times 15 \mathrm{~mL})$ and stirred with solid $\mathrm{NaHCO}_{3}$. After the usual procedure, a yellowish semi-solid was obtained $(0.26 \mathrm{~g}, 0.72 \mathrm{mmol}$, $70 \%$ ) and purified by flash column chromatography (hexane/ethyl acetate 90:10 and 50:50). Column fractions were characterized by spectroscopic analyzes as oxime $\mathbf{8}$ $\left(\mathrm{R}_{\mathrm{t}} 22.8 \mathrm{~min}\right)$, and isoxazol $9\left(\mathrm{R}_{\mathrm{t}} 13.4 \mathrm{~min}\right)$.

\section{Results and Discussion}

The reaction sequence for the preparation of precursors 7, 8 and 9 was initiated with the classical oxidation of cycloocta-1,5-diene (2), ${ }^{9-11}$ to obtain diol 3, which was obtained with its $\mathbf{3 a}$ isomer in $85 \%$ yield. The separation of the diol $\mathbf{3}$ from the isomeric mixture $\mathbf{3}$ and $\mathbf{3 a}$ was done by successive fractional recrystallizations of ethyl acetate.

High resolution mass spectrometry (MS) confirmed the exact molar mass (158.0946 $\left.\mathrm{g} \mathrm{mol}^{-1}\right)$ and provided the characteristic fragments of the molecule. The elemental analysis data $(9.11 \% \mathrm{H}, 54.52 \% \mathrm{C})$ presented a variation when compared with the theoretical data $(8.92 \% \mathrm{H}$, $60.74 \%$ C). ${ }^{9}$ This difference is related to the presence of water of crystallization in the structure of diol $\mathbf{3}$, which

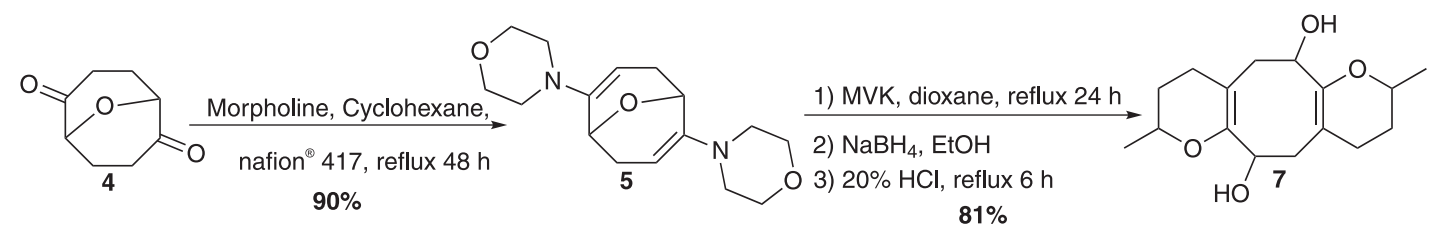

Scheme 3. Reaction conditions for synthesis of enol ether 7.

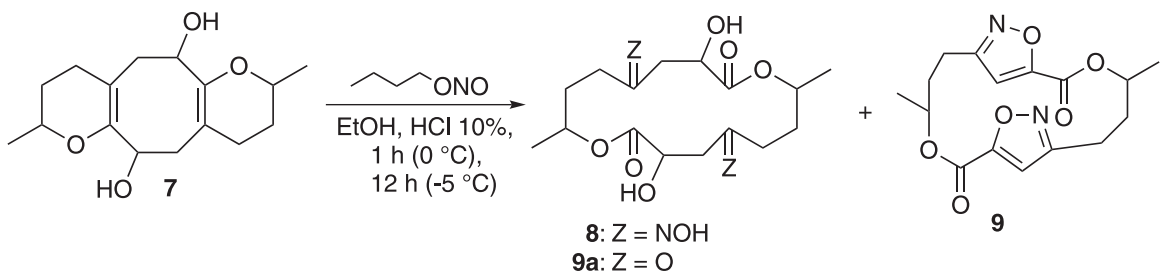

Scheme 4. Reaction conditions for expansion of enol ether 7. 
assertion is confirmed when the data obtained are compared with the theoretical data containing water of crystallization in the calculations $(9.15 \% \mathrm{H}, 54.53 \% \mathrm{C}) .{ }^{9}$

The conversion of 9-oxabicyclo[3.3.1]nonane2,6-diol (3) to 2,6-dioxo-9-oxabicyclo[3.3.1]nonane (4) was successfully achieved in $99 \%$ yield from the use of the oxidant 2-iodoxybenzoic acid oxidant. ${ }^{12}$ High resolution mass spectrometry (MS) confirmed the exact molar mass $(\mathrm{m} / \mathrm{z}$ 154.0629) and provided the characteristic fragments of the molecule. Data from the elemental analysis $(6.51 \% \mathrm{H}$, $62.20 \%$ C) were consistent with the theoretical data $(6.54 \% \mathrm{H}, 62.33 \% \mathrm{C}){ }^{9}$

Gross enamine 5, obtained from diketone 4, was alkylated, reduced and hydrolyzed in a same pot and provided precursor 7, which had its structure elucidated from spectrometric techniques including 1D and 2D NMR.

The infrared spectrum analysis of enol ether 7 showed the $\mathrm{OH}$ bands at $3393 \mathrm{~cm}^{-1}, \mathrm{C}=\mathrm{C}$ at $1704 \mathrm{~cm}^{-1}$, and $\mathrm{C}-\mathrm{O}$ at the region of 1015 to $1200 \mathrm{~cm}^{-1}$, present in the cyclized product 7 . The hydroxyls present proved that the $\mathrm{C}-\mathrm{O}$ related bonds of the bridging heads of the bicyclic system 4 were broken. The absorption at $1704 \mathrm{~cm}^{-1}$ relative to the $\mathrm{C}=\mathrm{C}$ bond, although relatively high for the tetrasubstituted unsaturated groups, has been reported in the literature for enol ethers. ${ }^{13}$

To verify the chemical purity of product 7 , a low resolution mass spectrometry (MS) analysis was performed, which showed molar mass $281 \mathrm{~g} \mathrm{~mol}^{-1}$ and the characteristic fragmentations. The elemental analysis data $(68.42 \% \mathrm{C}$, $8.88 \% \mathrm{H})$ are consistent with the theoretical data (68.54\% C, $8.63 \% \mathrm{H})$.

The ${ }^{1} \mathrm{H}$ NMR spectrum $\left(300 \mathrm{MHz}, \mathrm{CDCl}_{3}\right.$ ) of product 7 showed two doublets at $\delta 1.22$ and 1.27 for the methyls of probable isomers. The absorptions in $\delta 1.54$ to 2.42 relative to the $\mathrm{CH}_{2}$, as well as the 7 hydrogens relative to the $\mathrm{CH}$ recorded in the region of $\delta 3.75$ to 4.15 , were related to the probable stereoisomers of the product 7 .

The ${ }^{13} \mathrm{C}$ NMR spectrum $\left(75.46 \mathrm{MHz}, \mathrm{CDCl}_{3}\right.$ ) showed the quaternary carbons of the ether enol 7 at $\delta 101.5,102.3$, 143.8 and 145.3, absent in the DEPT spectrum.

The absorptions of $\mathrm{CH}_{2}(\delta 21.0$ to 35.0$)$ and of $7 \mathrm{CH}_{\mathrm{s}}$ ( $\delta 66.0$ to 72.0 ) confirmed the stereoisomers of the enol ether 7.

By the 2D NMR techniques, some correlations of ${ }^{1} \mathrm{H},{ }^{1} \mathrm{H}$ and ${ }^{1} \mathrm{H},{ }^{13} \mathrm{C}$ were observed, which aided in the structural elucidation of the isomeric mixture of 7. The gCOSY (correlation spectroscopy) spectrum showed the methyl groups $(\delta 1.22$ and 1.27) coupled with $\mathrm{CH}(\delta$ 4.05-4.15 and $\delta 3.75-3.82$ ), respectively.

The gHMBC (heteronuclear multiple bond correlation) experiment confirmed the $\mathrm{sp}^{2}$ carbons $(\delta 144.3,145.5$ and $\delta 102.0,102.5)$ tetrasubstituted not shown in the gHMQC (heteronuclear multiple quantum correlation) spectrum.

Posteriorly, it was observed in CGC (capillary column gas chromatography) (DB-1) that compound 7, submitted to successive recrystallizations, was enriched by one of the isomers. The analysis of ${ }^{1} \mathrm{H} \mathrm{NMR}\left(300 \mathrm{MHz}, \mathrm{CDCl}_{3}\right)$ found different intensities of the two methyl groups.

The expansion of bicyclic ethers can be promoted by oxidative cleavage methods, such as ozonolysis, ${ }^{14,15}$ oxidation with $m$-chloroperbenzoic acid ${ }^{14}$ and hydrolytic nitrosation. ${ }^{16-20}$ In this work, to expand ring 7, ozonolysis reactions and oximation/deoximation reactions were used.

The ozonolysis reaction was studied with substrate 7 under reaction conditions described in the literature. ${ }^{14,15}$ However, the products obtained with this reaction provided mixtures of compounds that could not be elucidated by means of spectroscopic analyzes.

The expansion of bicyclic ether enol by hydrolytic nitrosation with butyl nitrite was developed in our laboratory for the production of macrolide pyrenophorin $(\mathbf{1}),{ }^{8}$ which resulted in an isomeric mixture (70\%) formed mainly by dioximedilactone 8 and diisoxazoledilactone 9 (Scheme 4), in which traces of diketodilactone $\mathbf{9 a}$ could be observed in the NMR and IR spectra.

The CGC analysis (DB-1) showed a mixture of compounds 8 and 9 which were obtained (60-70\%) with the butyl nitrite oxidant.

The IR spectra presented the vibrational frequencies of lactone $\left(1726 \mathrm{~cm}^{-1}\right)$ and oxime $\left(1604 \mathrm{~cm}^{-1}\right) .{ }^{1} \mathrm{H}$ NMR (300 MHz, DMSO- $d_{6}$ ) and ${ }^{13} \mathrm{C}$ NMR (75.46 MHz, DMSO- $d_{6}$ ) spectra showed characteristic absorptions of the oxime $\mathbf{8}$ and ketolactone 9a (see Supplementary Information).

Subsequently, the product mixture was purified by flash chromatographic column (hexane/ethyl acetate 90:10 and 50:50) to provide enriched fractions of $\mathrm{R}_{\mathrm{t}} 15.9$; 13.4 and 22.8 min, previously observed by CGC.

The solid fractions of $\mathrm{R}_{\mathrm{t}} 13.4$ and 22.8 min observed in the CGC (DB-1) and ${ }^{1} \mathrm{H}$ NMR (300 MHz, $\mathrm{CDCl}_{3}$ ), remained as main components even undergoing successive recrystallizations.

Afterwards this fraction was maintained in $\mathrm{CDCl}_{3}$ solution and cooling for 2 days, there was enrichment of the $\mathrm{R}_{t}$ compound of 13.4 min (DB-1). ${ }^{1} \mathrm{H}$ NMR spectroscopic analyzes $\left(300 \mathrm{MHz}, \mathrm{CDCl}_{3}\right.$ ) and ${ }^{13} \mathrm{C} \mathrm{NMR}(75.49 \mathrm{MHz}$, $\mathrm{CDCl}_{3}$ ) showed a structure of the compound of $\mathrm{R}_{\mathrm{t}} 13.4 \mathrm{~min}$, being probably the isoxazole 9 .

In the isoxazole compound $\mathbf{9}$, the prominent singlet at $\delta 5.80$, related to $\mathrm{CH} \mathrm{sp}{ }^{2}$, was characterized by the DEPT, gHMQC, gHMBC techniques.

The chemical displacement of the oxime $\mathbf{8}$ in $\delta 10.15$ 
was not observed maybe because of the low concentration of this isomer in the compound mixture. In the ${ }^{1} \mathrm{H}$ NMR spectra $\left(300 \mathrm{MHz}\right.$, DMSO- $\left.d_{6}\right)$ doublets, with chemical shift $\delta 5.09,5.11,5.84$ and $5.89 \mathrm{ppm}$, were obtained resulting from labile hydrogen interactions of the compounds of the mixture 9 and $9 \mathbf{a}$ with this deuterated solvent.

\section{Conclusions}

The key intermediate 7 was prepared from the cheap starting material $\mathbf{3}$ in three steps and transformed into $\mathbf{8}$ and 9 in excellent yields. The conversion of the $\mathbf{8}$ and 9 compounds into dilactone $\mathbf{1}$ is under investigation and will be reported in due course.

\section{Supplementary Information}

Supplementary information associated with this work (NMR spectra $\left({ }^{1} \mathrm{H}\right.$ and $\left.{ }^{13} \mathrm{C}\right)$, infrared and elementary analysis) is available free of charge at http://jbcs.sbq.org.br as PDF file.

\section{Acknowledgments}

The authors are grateful to the Brazilian agencies $\mathrm{CNPq}$ and FINEP (grant CT-INFRA 970/01) for financial support, FAPEG/CAPES and PROBIP-2016/UEG.

\section{References}

1. Nozoe, S.; Hirai, K.; Tsuda, K.; Ishibashi, K.; Shirasaka, W.; Grove, J. F.; Tetrahedron Lett. 1965, 51, 4675.
2. Aliferis, K. A.; Chrysayi-Tokousbalides, M.; Fasseas, C.; Plant Physiol. Biochem. 2006, 44, 851.

3. Kalita, D.; Klan, A. T.; Saikia, A. K.; Bez, G.; Barua, N. C.; Synthesis 1998, 7, 975.

4. Fürstner, A.; Thiel, O. R.; Ackermann, L.; Org. Lett. 2001, 3, 449.

5. Lee, C. W.; Grubbs, R. H.; J. Org. Chem. 2001, 66, 7155.

6. Rao, K. S.; Reddy, D. S.; Mukkanti, K.; Pal, M.; Iqbal, J.; Tetrahedron Lett. 2006, 47, 6623.

7. Ramakrishna, K.; Sreenivasulu, R.; Vidavalur, S.; Reddy, B. J. M.; Lett. Org. Chem. 2016, 13, 693.

8. Mahajan, J. R.; Araújo, H. C.; Synthesis 1981, 49.

9. Duthaler, R. O.; Wicker, K.; Ackermann, P.; Ganter, C.; Helv. Chim. Acta 1972, 55, 1809.

10. Eaton, P. E.; Millikan, R.; Synthesis 1990, 483.

11. Hegemann, K.; Fröhlich, R.; Haufe, G.; Eur. J. Org. Chem. 2004, 2181.

12. More, J. D.; Finney, N. S.; Org. Lett. 2002, 4, 3001.

13. Mahajan, J. R.; Araújo, H. C.; Synthesis 1976, 111.

14. Mahajan, J. R.; Ferreira, G. A. L.; Araújo, H. C.; Nunes, B. J.; Synthesis 1976, 112.

15. Mahajan, J. R.; Araújo, H. C.; Synthesis 1975, 53.

16. Mahajan, J. R.; Ferreira, G. A. L.; Araújo, H. C.; J. Chem. Soc., Chem. Commun. 1972, 1078.

17. Mahajan, J. R.; Araújo, H. C.; Synthesis 1980, 64.

18. Mahajan, J. R.; Resck, I. S.; Synthesis 1980, 998.

19. Mahajan, J. R.; Monteiro, M. B.; J. Chem. Res. 1980, 264.

20. Mahajan, J. R.; Araújo, H. C.; Synthesis 1981, 49.

Submitted: April 16, 2017

Published online: June 23, 2017 